\title{
An Alternative Conversion Technique for Salvaging a Failed lleal J-Pouch-Anal Anastomosis to a Modified H-Pouch
}

\author{
Toshimitsu Araki Chikao Miki Shigeyuki Yoshiyama Yoshiki Ohkita \\ Hiromi Yasuda Masato Kusunoki \\ Department of Gastrointestinal and Pediatric Surgery, Mie University Graduate School of Medicine, Tsu, Japan
}

\section{Key Words}

Ulcerative colitis · Restorative proctocolectomy •

Pouch reconstruction

\begin{abstract}
Ileal J-pouch-anal anastomosis is a commonly accepted surgical treatment for patients with ulcerative colitis. However, making a J-pouch anal anastomosis can be difficult due to anatomical variations of patients. We experienced an informative case of ulcerative colitis in which the ileal pouch was damaged when it was pulled down into the anal canal because of a fatty short mesentery. To preserve intestinal consistency and functioning fecal continence, a modified $\mathrm{H}$-pouch was converted from a damaged J-pouch and anastomosed to the dentate line. This operation achieved a satisfactory functional result and, we believe, presents an option for reconstructing ileal J-pouch-anal anastomosis.
\end{abstract}

Copyright $\odot 2007$ S. Karger AG, Basel

\section{Introduction}

Since the ileal J-pouch-anal anastomosis (IPAA) was introduced by Utsunomiya et al. [1] in 1980, it has become the most widely accepted procedure for surgical treatment of patients with ulcerative colitis (UC) and familial adenomatous polyposis. The functional results are gener- ally good and patient satisfaction is high [2]. Although it is important to create a tension-free anastomosis between the ileal pouch and the dentate line, as well as to preserve a sufficient length of terminal ileum for improved fecal continence after surgery [3], it is sometimes difficult for the ileal pouch to reach the anastomotic site at the dentate line because of excessive fat deposition in the mesentery or a narrow pelvic canal. Moreover, accidental iatrogenic injury can occur to the pouch when the apex of the loop is pulled down into the anastomotic site through the narrow pelvic canal. Such loss of the pouch is especially troubling for younger patients who face a permanent ileostomy for perhaps the next 50-60 years of their lives. Consideration needs to be given to salvage maneuvers that might at the outset seem extreme.

We experienced a case of UC in which the vascular supply of the apex of the ileal loop had been insufficient due to injury to the marginal arteries. We successfully treated the patient using a pouch reconstruction technique that converted a damaged J-pouch to a modified H-pouch.

\section{Case Presentation}

A 37-year-old man suffered from UC since he had been 29 years old. We scheduled IPAA after he was referred to our department for surgical treatment.

\section{KARGER}

Fax +41613061234 E-Mail karger@karger.ch www.karger.com
(C) 2007 S. Karger AG, Basel

$0253-4886 / 07 / 0245-0324 \$ 23.50 / 0$

Accessible online at:

www.karger.com/dsu
Toshimitsu Araki

Department of Gastrointestinal and Pediatric Surgery

Mie University Graduate School of Medicine

Edobashi 2-174, Tsu, Mie 514-8507 (Japan)

Tel. +81 592231 5294, Fax +81 592232 6968, E-Mail taraki@clin.medic.mie-u.ac.jp 
Fig. 1. Conversion technique from J-pouch to modified H-pouch. a The discolored apex (\#) and the top of the J-pouch $\left(^{*}\right)$ were transected using a linear staple cutter. b The terminal ileum anastomosed sideto-side was turned upside down and the amputation stump of the oral side ileum was pulled down. c Small enterotomies were made $4 \mathrm{~cm}$ proximal to the ileum end and $1 \mathrm{~cm}$ proximal to the stapled line of the pouch. Side-to-side anastomosis was performed between the ileum and the pouch using the TLC 75, with a spout length of $3 \mathrm{~cm}$. d The end of the H-pouch was anastomosed to the anus at the dentate line using interrupted 3-0 Vicryl sutures.


The colon was dissected free in the Lloyd-Davies position. The ileum was divided close to the ileocolic junction, preserving the ileal branch of the ileocolic vessels. Since the ileal mesentery was too short to achieve a tension-free ileal pouch-anal anastomosis, the superior mesenteric artery and vein were divided and the avascular area of the mesentery was cut transversely. Care was taken to preserve the ileocolic vessels. When an 8 F Nelaton catheter was inserted through the mesentery to trace down the apex of the loop, the ileal mesentery was torn and the vascular branches to the apex were also accidentally injured. Since it seemed likely that the vascular supply to the apex of the ileal loop was sufficient, a J-pouch was constructed and total mucosal proctectomy was simultaneously performed. At the time of the pouch-anal anastomosis, we noticed that the apex of the J-pouch had become discolored. We decided to dissect the discolored apex of the Jpouch and reconstruct the pouch. At the top of the J-pouch, the bowel was transected using a linear staple cutter (TLC 75; Ethicon Inc.; fig. 1a). The terminal ileum anastomosed side-to-side was turned upside down and the amputation stump of the oral side ileum was pulled down (fig. 1b). Small enterotomies were made $4 \mathrm{~cm}$ proximal to the ileum end and $1 \mathrm{~cm}$ proximal to the stapled line of the pouch. Side-to-side anastomosis was performed between the ileum and the pouch using the TLC 75 with a spout length of $3 \mathrm{~cm}$ (fig. 1c). The enterotomy site was closed using a linear stapling instrument (TX60; Ethicon Inc.). The end of the $\mathrm{H}$-pouch was anastomosed to the anus at the dentate line using interrupted 4-0 Vicryl sutures (fig. 1d). A diverting loop ileostomy was constructed. 
Fig. 2. Defecography using barium after ileal H-pouch-anal anastomosis. a The pouchogram shows no incontinence and there is good pouch capacity at rest. b With straining, the barium in the pouch was evacuated smoothly.
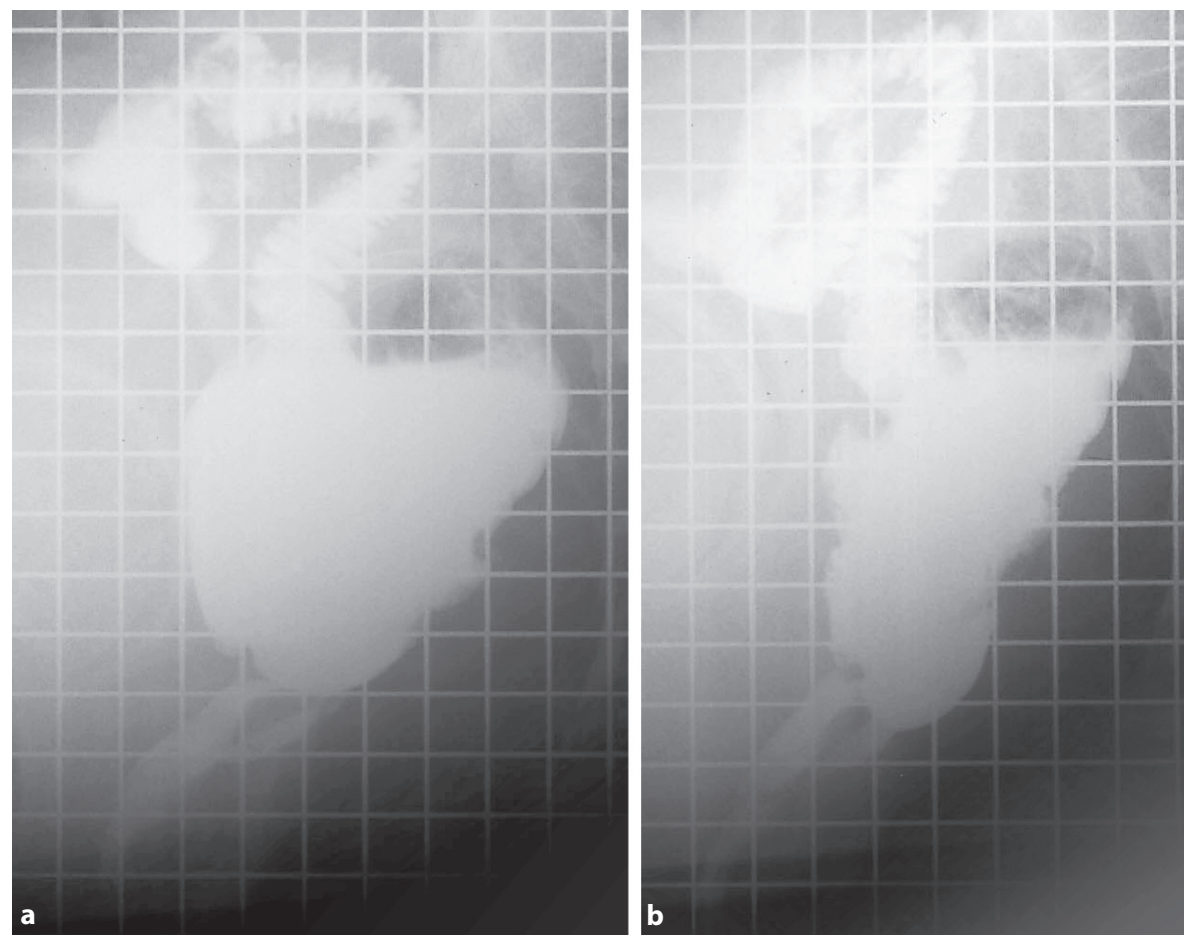

Although the postoperative course was uneventful, an anastomotic stenosis developed 2 months after the operation and the patient required mechanical dilatation using a dilatable bougie until closure of the ileostomy. Three months after surgery, defecography using barium showed sufficient ileal pouch volume (fig. 2b) and smooth evacuation from the anus (fig. 2a); the patient then underwent closure of the ileostomy. The mean frequency of daily evacuations was 6 , and there has been no soiling, incontinence, recurrence of anastomotic stenosis or outlet obstruction at 2 years after closure of the ileostomy.

\section{Discussion}

There are 2 elements to fecal continence: sphincter continence and reservoir continence. After restorative proctocolectomy, it is especially important to preserve reservoir continence [4]. Many types of reservoir that help to achieve optimal fecal continence have been reported [1, $5,6]$. Among them, the $\mathrm{S}$ - or $\mathrm{H}$-shaped ileal pouch, which has efferent limbs positioned between the pouch and the anal canal, sometimes leads to outflow obstruction and incomplete evacuation [7]. By contrast, the J- or W-shaped ileal pouch serves as an adequate neorectal reservoir after proctocolectomy $[1,8]$. These pouches, anastomosed directly to the anal canal, are as distensible and capacious and as readily evacuated as a healthy rectum.
However, many large series of IPAAs from specialized institutions have revealed a failure rate of J-pouches after the initial operation ranging from 5.3 to $18.6 \%$ [9-12], putting patients at risk of permanent ileostomy. These are technically complex procedures and the technique requires a sufficient length of small bowel mesentery. Also, it is more difficult to reconstruct an ileal pouch in a salvage procedure for pelvic sepsis after an initial IPAA in hazardous cases $[2,9,11,12]$.

In the present case, we dissected a discolored apex of a J-pouch and converted it to a modified $\mathrm{H}$-pouch for reconstruction with IPAA. We also paid attention to making the spout a long efferent limb to avoid outlet obstruction that may frequently develop as a late complication of this procedure [13].

In conclusion, the conversion of a damaged J-pouch to a modified $\mathrm{H}$-pouch-anal anastomosis may be an optional technique for reconstructing IPAA. This surgical technique can allow preservation of intestinal continuity and acceptable fecal continence for patients after IPAA. 


\section{References}

1 Utsunomiya J, Iwama T, Imajo M: Total colectomy, mucosal proctectomy, and ileoanal anastomosis. Dis Colon Rectum 1980;23: 459-466.

2 Fazio VW, Ziv Y, Church JM, et al: Ileal pouch-anal anastomoses complications and function in 1,005 patients. Ann Surg 1995; 222:120-127.

-3 Tomita R, Fujisaki S, Tanjoh K: Relationship between gastrointestinal transit time and daily stool frequency in patients after ileal J pouch-anal anastomosis for ulcerative colitis. Am J Surg 2004;187:76-82.

4 Karlan M, McPherson RC, Watman RN: An experimental evaluation of fecal continence - sphincter and reservoir - in the dog. Surg Gynecol Obstet 1959;108:469-475.
5 Ferrari BT, Fonkalsrud EW: Endorectal ileal pullthrough operation with ileal reservoir after total colectomy. Am J Sur 1978;136: 113-121

6 Parks AG, Nicholls RJ: Proctocolectomy without ileostomy for ulcerative colitis. $\mathrm{Br}$ Med J 1978;8:85-88.

7 Nicholls RJ: Restorative proctocolectomy with various types of reservoir. World J Surg 1987;11:751-762.

8 Nicholls RJ, Lubowski DZ: Restorative proctocolectomy: the four loop (W) reservoir. $\mathrm{Br}$ J Surg 1987;74:564-566.

9 Heuschen UA, Allemeyer EH, Hinz U, Lucas M, Herfarth C, Heuschen G: Outcome after septic complications in J pouch procedures. Br J Surg 2002;89:194-200.
10 Ogunbiyi OA, Korsgen S, Keighley MR: Pouch salvage: long-term outcome. Dis Colon Rectum 1997;40:548-552.

$\checkmark 11$ Dayton MT, Larsen KP: Outcome of pouchrelated complications after ileal pouch-anal anastomosis. Am J Surg 1997;174:728-731.

12 Zmora O, Efron JE, Nogueras JJ, Weiss EG, Wexner SD: Reoperative abdominal and perineal surgery in ileoanal pouch patients. Dis Colon Rectum 2001;44:1310-1314.

13 Fonkalsrud EW, Loar N: Long-term results after colectomy and endorectal ileal pullthrough procedure in children. Ann Surg 1992;215:57-62. 